\title{
GERMINAÇÃO DE SEMENTES E VIGOR DE PLÂNTULAS DE MILHO SUBMETIDAS AO ESTRESSE SALINO INDUZIDO POR DIFERENTES SAIS ${ }^{1}$
}

\author{
LENITA APARECIDA CONUS ${ }^{2}$; PAULO CÉSAR CARDOSO ${ }^{3}$; LUCIANO DOS REIS VENTUROSO3; \\ SILVANA DE PAULA QUINTÃO SCALON ${ }^{4}$
}

\begin{abstract}
RESUMO - O objetivo do trabalho foi avaliar o efeito do estresse salino induzido por diferentes potenciais osmóticos das soluções de $\mathrm{NaCl}, \mathrm{KCl}$ e $\mathrm{CaCl}_{2}$, na germinação de sementes e no vigor de plântulas de milho. $\mathrm{O}$ trabalho foi constituído por dois experimentos realizados no Laboratório de Sementes da Universidade Federal da Grande Dourados e em casa de vegetação da Embrapa Agropecuária Oeste, Dourados-MS. O delineamento experimental utilizado foi inteiramente casualizado, em arranjo fatorial 3 × 6 , com quatro repetições, sendo o primeiro fator constituído pelos sais e o segundo pelos potenciais osmóticos: 0,$0 ;-0,2 ;-0,4 ;-0,8 ;-1,2 \mathrm{e}-1,6 \mathrm{MPa}$. Foram analisadas as variáveis: Experimento 1 - porcentagem de germinação, comprimento de parte aérea e comprimento da raiz primária; Experimento 2 - altura final de planta, comprimento radicular, diâmetro de colmo, área foliar, teor de clorofila e massa seca de parte aérea e de raiz. A germinação não foi afetada pelo estresse salino. A diminuição do potencial osmótico nas soluções de $\mathrm{KCl}$ e $\mathrm{NaCl}$, causou decréscimos no comprimento de parte aérea e acréscimos no comprimento da raiz primária. A condição de estresse provocada pelos sais proporciona comportamento diferenciado no vigor de plântulas de milho. O efeito salino do $\mathrm{NaCl}$ é maior nas características altura de planta, comprimento radicular, área foliar e massa seca de raiz.
\end{abstract}

Termos para indexação: Zea mays L., salinidade, $\mathrm{KCl}, \mathrm{CaCl}_{2}, \mathrm{NaCl}$

\section{SEED GERMINATION AND VIGOR OF CORN PLANTS SUBMITTED TO SALINE STRESS INDUCED BY DIFFERENT SALTS}

\begin{abstract}
The objective of this research was to evaluate the effect of saline stress induced by different osmotic potentials of $\mathrm{NaCl}, \mathrm{KCl}$ and $\mathrm{CaCl}_{2}$ solutions, on seed germination and vigor of corn plants. The experiment was consisted of two experiments that were carried out in the Seed Laboratory of the Federal University of Grande Dourados and in a green house at Embrapa Agropecuaria Oeste, in Dourados, MS. A randomized complete design was used in a 3 x 6 factorial arrangement, with four replications. The first factor was salts and the second the osmotic potentials: $0.0 ;-0.2 ;-0.4 ;-0.8 ;-1.2$ and -1.6MPa. The following variables were analyzed: Experiment 1 - germination percentage, shoot and root length; Experiment 2 - final plant height, root length, stem diameter, leaf area, chlorophyll content, and aerial part and root dried matter. Germination was not affected by saline stress. The decrease in osmotic potential in the $\mathrm{KCl}$ and $\mathrm{NaCl}$ solutions resulted in decreases in shoot length and increases in root length. Stress that was induced by salts promoted different performance for corn plant vigor. The saline effect of $\mathrm{NaCl}$ was greater on the characteristics plant height, root growth, leaf area and root dried matter.
\end{abstract}

Index terms: Zea mays L., salinity, $\mathrm{KCl}, \mathrm{CaCl}_{2}, \mathrm{NaCl}$

${ }^{1}$ Submetido em 06/11/2008. Aceito para publicação em 16/07/2009.

${ }^{2}$ Eng. Agr., mestranda em Agronomia da Faculdade de Ciências Agrárias, Universidade Federal da Grande Dourados, Cx. Postal 533, 79804-970, Dourados; bolsista CNPq, lenitaconus@yahoo.com.br.
${ }^{3}$ Eng. Agr., doutorandos em Agronomia da FCA/UFGD, bolsistas FUNDECT-MS/ CAPES E-mail cesarcardosop@hotmail.com, luck_rv@hotmail.com.

${ }^{4}$ Bióloga, Professora adjunta da FCA/UFGD, silvana.scalon@ufgd.edu.br. 


\section{INTRODUÇÃO}

O cultivo de milho (Zea mays L.) consolidou-se no Brasil com expressivo crescimento em área, produção e produtividade, basicamente nas regiões Sul, Centro-Oeste e Sudeste. Essa cultura possui elevado potencial produtivo e acentuada habilidade fisiológica na conversão de carbono mineral em compostos orgânicos, os quais são translocados das folhas e de outros tecidos fotossinteticamente ativos para locais onde serão estocados ou metabolizados. Além disso, apresenta pequena plasticidade foliar, reduzida prolificidade e baixa capacidade de compensação efetiva (Andrade, 1995; Fancelli e Dourado-Neto, 1997).

Dentre os fatores limitantes ao rendimento agronômico das culturas, a disponibilidade de nutrientes assume grande importância para a maioria dos solos brasileiros, devendose adicionar esses minerais nas quantidades, na forma e no momento mais adequado à planta. Entretanto, em algumas situações, onde não se faz o manejo integrado da adubação e da irrigação para assegurar a sustentabilidade da agricultura, podem ocorrer aumentos na concentração de sais no solo que inviabilizam o cultivo da maioria das plantas naquele local (Tôrres et al., 2004).

A alta concentração de sais é um fator de estresse para as plantas, pois reduz o potencial osmótico do solo, dificulta a absorção de água pelas raízes e aumenta a concentração de íons no protoplasma (Amorim et al., 2002), sendo fator limitante para o crescimento e a produção das culturas, induzindo a modificações morfológicas, estruturais e metabólicas nas plantas superiores.

A resistência à salinidade é descrita como a habilidade das plantas de evitar, por meio de uma regulação salina, que excessivas quantidades de sal provenientes do substrato alcancem o protoplasma, e também, de tolerar os efeitos tóxicos e osmóticos associados ao aumento da concentração de sais. Essa adaptação das plantas ao estresse vem sendo avaliada pela capacidade germinativa das sementes e pela análise de crescimento. A cultura do milho enquadra-se como moderadamente tolerante à salinidade, podendo sofrer reduções progressivas do crescimento com o aumento da concentração de sais no meio radicular (Larcher, 2000).

As concentrações de sais que restringem o crescimento e manifestam os efeitos tóxicos nas plantas dependem do grau de resistência à salinidade da espécie, bem como do tempo de exposição, do estádio de desenvolvimento e tipo de sal utilizado (Ferreira e Rebouças, 1992).

Santos et al. (1992) e Dickmann et al. (2005) observaram que o $\mathrm{CaCl}_{2}$ apresentou-se mais prejudicial que o $\mathrm{NaCl}$, na germinação de sementes de soja e girassol respectivamente. Os autores relataram inibição da germinação com o uso de $\mathrm{CaCl}_{2}$ no potencial de $-1,2 \mathrm{MPa}$, enquanto que para o $\mathrm{NaCl}$ essa inibição ocorreu apenas a $-1,5 \mathrm{MPa}$. As culturas apresentam sensibilidade diferenciada em relação aos tipos de sais, como demonstrado por Fanti e Perez (2004) que encontraram inibição de $50 \%$ da germinação de sementes de paineira para $\mathrm{CaCl}_{2}$ e $\mathrm{NaCl}$, no potencial osmótico de $-0,6 \mathrm{MPa}$, sendo que a tolerância ao $\mathrm{KCl}$ foi maior, ocorrendo inibição somente a - 0,8MPa. Existem inclusive, diferenças entre cultivares da mesma espécie, como citado por Moterle et al. (2006) em trabalhos com estresse salino em milho pipoca.

Sustentado na hipótese de que para cada sal existem níveis de potencial osmótico que venham a causar danos as culturas, objetivou-se com o trabalho avaliar o efeito do estresse salino induzido por diferentes potenciais osmóticos das soluções de cloreto de sódio $(\mathrm{NaCl})$, de potássio $(\mathrm{KCl})$ e de cálcio $\left(\mathrm{CaCl}_{2}\right)$, na germinação de sementes e no vigor de plântulas de milho.

\section{MATERIAL E MÉTODOS}

O trabalho foi constituído por dois experimentos, realizados no Laboratório de Sementes da Universidade Federal da Grande Dourados e em casa de vegetação da Embrapa Agropecuária Oeste, em Dourados-MS, no período de abril a maio de 2008. Para condução dos trabalhos foram utilizadas sementes de milho da cultivar BRS-3003.

O delineamento experimental utilizado foi inteiramente casualizado, com os tratamentos arranjados em um fatorial $3 \times 6$, com quatro repetições. O primeiro fator foram os sais: $\mathrm{NaCl}, \mathrm{KCl}$ e $\mathrm{CaCl}_{2}$ e o segundo foi composto de seis potenciais osmóticos: 0,$0 ;-0,2 ;-0,4 ;-0,8 ;-1,2$ e -1,6MPa. As soluções salinas foram preparadas com água deionizada e a concentração dos sais obtidos a partir da equação de Van't Hoff, citada por Salisbury e Ross (1992).

No primeiro experimento foi realizado o teste de germinação, conforme as Regras para Análise de Sementes (Brasil, 1992). Para cada tratamento, foram utilizadas 200 sementes, distribuídas em quatro repetições de 50 sementes, colocadas em substrato de papel "germitest" para a confecção dos rolos, umedecidos com a quantidade das soluções salinas equivalente a 2,5 vezes a massa do papel seco, sendo envolvidos em sacos plásticos e mantidos em câmara de germinação regulada à temperatura constante de $25{ }^{\circ} \mathrm{C}$. A contagem foi realizada no sétimo dia após a 
semeadura e os resultados expressos em porcentagem de plântulas normais. Após o teste de germinação, realizouse análise de desenvolvimento de plântulas, separando-se ao acaso 40 plântulas normais por tratamento, divididas em parte aérea $(\mathrm{CP})$ e raiz primária (CRP), determinandose o comprimento das mesmas, com o auxílio de régua graduada.

Para o segundo experimento, conduzido em casa de vegetação, as sementes foram embebidas por 18 horas em recipientes contento as soluções descritas anteriormente, sendo as testemunhas embebidas em água deionizada, e mantidas em câmara de germinação a temperatura de $25{ }^{\circ} \mathrm{C}$. Posteriormente foram semeadas três sementes em vasos contendo $500 \mathrm{~g}$ de solo classificado como Latossolo Vermelho distroférrico. Procedeu-se a irrigação com as soluções salinas até o início da emergência, e posteriormente com água destilada, ambas, de modo a manter o teor de água do solo próximo a $60 \%$ do volume total de poros. $\mathrm{O}$ desbaste foi realizado após a emergência, sendo conduzida a primeira planta que veio a emergir.

Para avaliação do efeito salino das soluções, aos 20 dias após a semeadura foram analisadas a altura final de planta (AP) e o comprimento radicular (CR), por meio da separação das raízes do solo com água corrente, e recuperadas mediante o uso de duas peneiras sobrepostas, com malhas de 0,25 e 1,00 mm de diâmetro, sendo aferidas com régua graduada. O diâmetro de colmo (DC) foi medido com paquímetro digital, a área foliar (AF) calculada pela fórmula proposta por Francis et al. (1969), o teor de clorofila (TC) determinado de forma não destrutiva, com clorofilômetro Minolta modelo SPAD-502 (Soil Plant Analysis Development), e massa seca da parte aérea (MSA) e raiz (MSR) determinada em estufa com circulação forçada de ar, regulada à temperatura de $60 \pm 2^{\circ} \mathrm{C}$, até a obtenção de massa constante.

Os resultados foram submetidos à análise de variância, utilizando-se o programa SISVAR. Verificando-se interação significativa entre os fatores, procederam-se os necessários desdobramentos, realizando-se para os sais comparação entre as médias por meio do teste de Tukey a $5 \%$ de probabilidade, e para os potenciais osmóticos foi realizado análise de regressão, sendo escolhido o modelo de maior grau significativo.

\section{RESULTADOS E DISCUSSÃO}

No experimento conduzido em laboratório, não houve resposta significativa para a germinação em nenhum dos fatores avaliados, sendo observado porcentagem de germinação da ordem de $90,8,91,6$ e $92,3 \%$ para $\mathrm{NaCl}$, $\mathrm{CaCl}_{2}$ e $\mathrm{KCl}$, respectivamente. Já Moterle et al. (2006), estudando a germinação de três cultivares de milho-pipoca, verificaram redução na porcentagem de plântulas normais de todas as cultivares com o decréscimo nos níveis de potencial osmótico de $\mathrm{KCl}$, sendo a germinação totalmente inibida quando as sementes foram submetidas ao menor potencial (-0,9MPa). Machado Neto et al. (2006), avaliando a germinação em sementes de feijão sob diferentes potenciais osmóticos, não encontraram diferenças significativas entre $\mathrm{CaCl}_{2}, \mathrm{NaCl}$ e $\mathrm{KCl}$ no potencial de $-0,6 \mathrm{MPa}$, entretanto, a $-1,2 \mathrm{MPa}$ o $\mathrm{CaCl}_{2}$ foi menos severo para a germinação em relação aos demais sais.

A análise de variância indicou efeito significativo da interação sal x potencial osmótico para o comprimento de parte aérea e da raiz primária. $\mathrm{O} \mathrm{CP}$ do milho foi inferior quando o substrato de germinação foi umedecido com soluções de $\mathrm{CaCl}_{2}$ e $\mathrm{KCl}$ no potencial osmótico de -0,2MPa (Tabela 1). Para os demais potenciais, o $\mathrm{KCl}$ manifestou decréscimos somente em -1,2 e -1,6MPa, comportamento semelhante ao $\mathrm{NaCl}$ no último potencial osmótico. Em relação ao $\mathrm{CRP}$, o $\mathrm{NaCl}$ apresentou os menores valores quando comparado aos demais sais, apresentando comprimento semelhante nos potenciais osmóticos estudados. $\mathrm{O} \mathrm{CaCl}_{2}$ proporcionou as menores variações para o $\mathrm{CP}$ e os maiores valores para o CRP nos potenciais osmóticos de - 0,2 a - $0,8 \mathrm{MPa}$, sem diferir do $\mathrm{KCl}$ nos demais potenciais, podendo indicar uma maior resistência das raízes aos efeitos desse sal. Esse fato pode estar relacionado com as funções do $\mathrm{Ca}^{+2}$ que além de ser essencial na manutenção da integridade da membrana plasmática, ativa um grande número de sistemas enzimáticos que regulam o crescimento da planta (Franco et al., 1999).

Os resultados obtidos tanto para o $\mathrm{CP}$ como para o CRP, não permitiram o ajuste de equações de regressão que expliquem o comportamento do $\mathrm{CaCl}_{2}$ no milho (Figuras 1 e 2). A redução dos potenciais osmóticos proporcionados pelo $\mathrm{NaCl}$ e $\mathrm{KCl}$, resultaram em respostas semelhantes sobre o CP, verificando-se uma relação diretamente proporcional, onde conforme reduzia-se o potencial osmótico havia decréscimos no CP (Figura 1). Constatou-se, no entanto, que no potencial de $-1,6 \mathrm{MPa}$, o $\mathrm{KCl}$ proporcionou redução de $36,6 \%$, sendo maior que a encontrada para o $\mathrm{NaCl}$ $(35,2 \%)$. Resultados semelhantes foram encontrados por Moterle et al. (2006), que observaram redução linear no comprimento da parte aérea das plântulas à medida que o potencial osmótico da solução de $\mathrm{KCl}$ foi diminuído. 
TABELA 1. Valores de comprimento de parte aérea (CP) e de raiz primária (CRP) de milho sob estresse salino induzido por três sais em diferentes potenciais osmóticos, em condições de laboratório.

\begin{tabular}{|c|c|c|c|c|c|c|}
\hline \multirow{2}{*}{ Sal } & \multicolumn{6}{|c|}{ Potencial osmótico (MPa) } \\
\hline & 0,0 & $-0,2$ & $-0,4$ & $-0,8$ & $-1,2$ & $-1,6$ \\
\hline & \multicolumn{6}{|c|}{$\mathrm{CP}(\mathrm{cm})$} \\
\hline $\mathrm{CaCl}_{2}$ & $9,27 \mathrm{a}$ & $7,06 \mathrm{~b}$ & $7,11 \mathrm{a}$ & $7,90 \mathrm{a}$ & $7,75 \mathrm{a}$ & $8,06 \mathrm{a}$ \\
\hline $\mathrm{NaCl}$ & $9,28 \mathrm{a}$ & $9,31 \mathrm{a}$ & $6,61 \mathrm{a}$ & $6,93 \mathrm{a}$ & $7,79 \mathrm{a}$ & $6,01 \mathrm{~b}$ \\
\hline $\mathrm{KCl}$ & $9,26 \mathrm{a}$ & $7,83 \mathrm{~b}$ & $7,14 \mathrm{a}$ & $7,81 \mathrm{a}$ & $6,40 \mathrm{~b}$ & $5,88 \mathrm{~b}$ \\
\hline \multirow[t]{2}{*}{$\mathrm{CV}(\%)$} & \multicolumn{6}{|c|}{8,1} \\
\hline & \multicolumn{6}{|c|}{$\mathrm{CRP}(\mathrm{cm})$} \\
\hline $\mathrm{CaCl}_{2}$ & $6,27 \mathrm{a}$ & $11,29 \mathrm{a}$ & $10,03 \mathrm{a}$ & $11,66 \mathrm{a}$ & $9,30 \mathrm{a}$ & $10,94 \mathrm{a}$ \\
\hline $\mathrm{NaCl}$ & $6,29 \mathrm{a}$ & $6,44 \mathrm{~b}$ & $5,93 \mathrm{~b}$ & $6,88 \mathrm{~b}$ & $6,46 \mathrm{~b}$ & $8,24 \mathrm{a}$ \\
\hline $\mathrm{KCl}$ & $6,28 \mathrm{a}$ & $7,03 \mathrm{~b}$ & $8,91 \mathrm{a}$ & $7,11 \mathrm{~b}$ & $9,10 \mathrm{ab}$ & $10,30 \mathrm{a}$ \\
\hline $\mathrm{CV}(\%)$ & \multicolumn{6}{|c|}{19,5} \\
\hline
\end{tabular}

Médias seguidas de mesma letra na coluna não diferem entre si pelo teste de Tukey a $5 \%$ de probabilidade

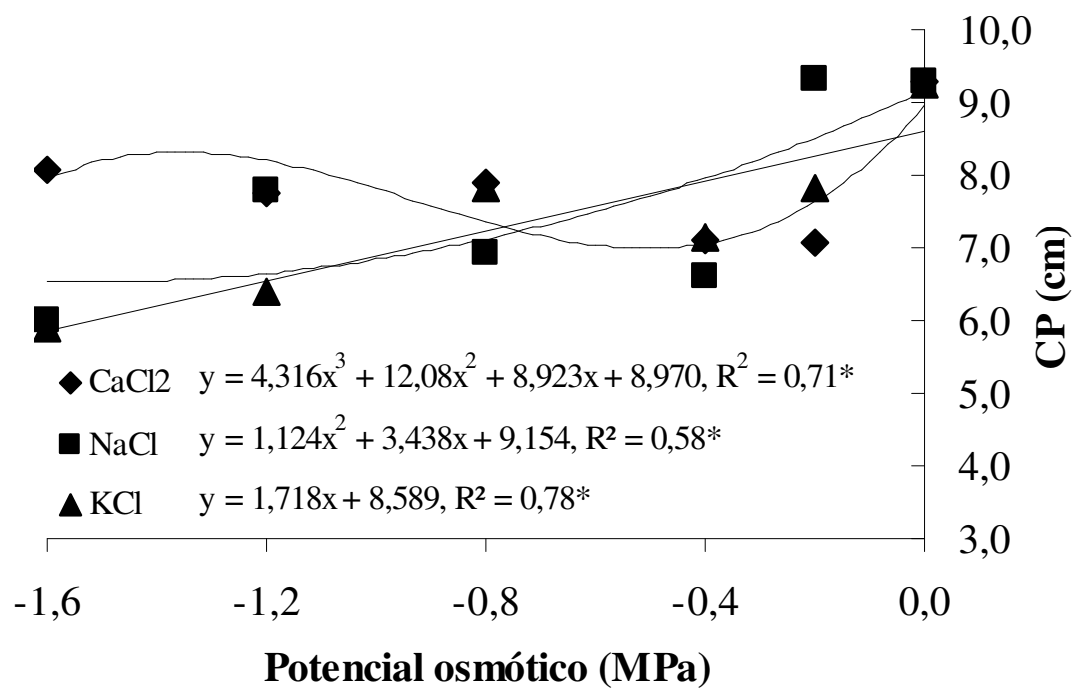

FIGURA 1. Comprimento de parte aérea (CP) de milho sob estresse salino induzido por três sais em diferentes potenciais osmóticos, em condições de laboratório.

Contrariamente ao $\mathrm{CP}$, ocorreram acréscimos do CRP com a diminuição dos potenciais osmóticos da solução de $\mathrm{KCl}$ e $\mathrm{NaCl}$ (Figura 2). Para o $\mathrm{KCl}$, a relação foi inversamente proporcional, relatando-se acréscimos de $2,08 \mathrm{~cm}$ (coeficiente angular) no CRP a cada uma unidade de variação $(1,0 \mathrm{MPa})$ que se diminuiu no potencial osmótico. Todavia, para o $\mathrm{NaCl}$, pode-se estimar por meio da equação, que o aumento no CRP foi mais pronunciado a partir de $-0,41 \mathrm{MPa}$, com crescimento da ordem de $6,18 \mathrm{~cm}$, chegando a $8,05 \mathrm{~cm}$ no menor potencial osmótico avaliado.

A literatura sugere que, em milho, as raízes parecem suportar melhor a salinidade que a parte aérea, fenômeno que pode estar associado ao ajustamento osmótico mais rápido e à perda de turgor mais lenta das raízes, quando comparadas com a parte aérea (Shalhevet et al., 1995). Além disso, o maior crescimento do sistema radicular pode contribuir para a tolerância ao estresse salino, em virtude do menor crescimento das partes com elevada capacidade transpiratória (Azevedo Neto et al., 1996). 


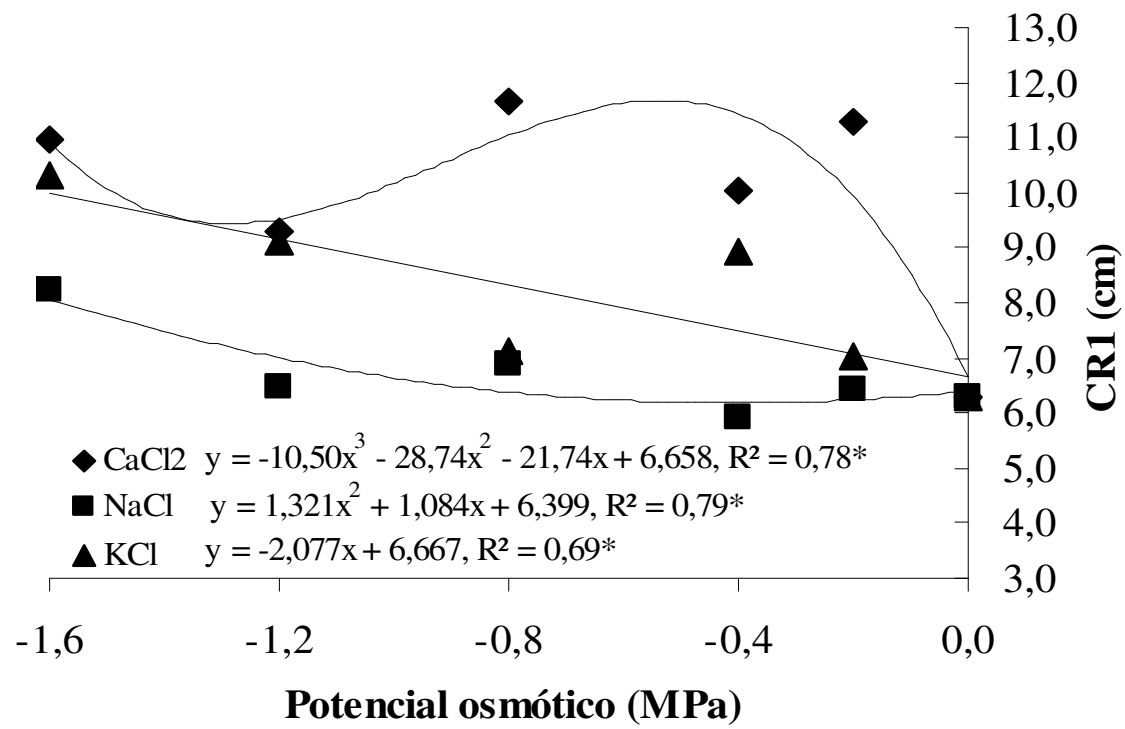

FIGURA 2. Comprimento da raiz primária (CRP) de milho sob estresse salino induzido por três sais em diferentes potenciais osmóticos, em condições de laboratório.

No experimento realizado em casa de vegetação, houve efeito significativo dos sais para a altura de planta, área foliar, teor de clorofila e massa seca de raiz. Para o crescimento radicular houve efeito dos fatores sais e potenciais osmóticos, entretanto, não houve interação desses fatores para essa variável. Já para o diâmetro do colmo a interação sal x potencial osmótico foi significativa. A massa seca da parte aérea não foi significativa para nenhum dos fatores avaliados, obtendo-se média de $0,15 \mathrm{~g}$ planta $^{-1}$.

Quando as sementes foram submetidas à solução de $\mathrm{NaCl}$ sofreram maior efeito do estresse, apresentando os menores valores para as variáveis $\mathrm{AP}$ e $\mathrm{AF}$, sem diferir entretanto, do $\mathrm{CaCl}_{2}$. Para $\mathrm{CR}$ e MSR os menores valores foram encontrados com o uso do $\mathrm{NaCl}$ e do $\mathrm{KCl}$ (Tabela 2). Da mesma forma, Azevedo Neto e Tabosa (2000), analisando o crescimento de cultivares de milho sob estresse salino induzido por $\mathrm{NaCl}$, obtiveram no nível mais alto de salinidade, decréscimos para a MSR e para a AF. O menor TC foi obtido com a exposição das plantas ao $\mathrm{KCl}$, porém, não diferiu do $\mathrm{NaCl}$. Plantas em ambiente salino apresentam alterações na organização dos cloroplastos, diminuindo assim, o conteúdo de clorofilas (Larcher, 2000).

TABELA 2. Altura de planta (AP), comprimento radicular (CR), área foliar (AF), teor de clorofila (TC), massa seca de raiz (MSR) e diâmetro de colmo (DC) de milho sob estresse salino induzido por três sais em diferentes potenciais osmóticos, em casa de vegetação.

\begin{tabular}{|c|c|c|c|c|c|c|c|c|c|c|c|}
\hline \multirow[t]{2}{*}{ Sal } & \multirow{2}{*}{$\begin{array}{l}\mathrm{AP} \\
(\mathrm{cm})\end{array}$} & \multirow{2}{*}{$\begin{array}{l}\mathrm{CR} \\
(\mathrm{cm})\end{array}$} & \multirow{2}{*}{$\begin{array}{l}\mathrm{AF} \\
\left(\mathrm{cm}^{2}\right)\end{array}$} & \multirow{2}{*}{$\begin{array}{l}\mathrm{TC} \\
(\%)\end{array}$} & \multirow{2}{*}{$\begin{array}{c}\text { MSR } \\
(\mathrm{g})\end{array}$} & \multicolumn{6}{|c|}{$\begin{array}{c}\text { DC }(\mathrm{cm}) \\
\text { Desdobramento Sal x Potencial osmótico }\end{array}$} \\
\hline & & & & & & 0,0 & $-0,2$ & $-0,4$ & $-0,8$ & $-1,2$ & $-1,6$ \\
\hline $\mathrm{CaCl}_{2}$ & $15,2 \mathrm{ab}$ & $42,0 \mathrm{a}$ & $55,0 \mathrm{ab}$ & $22,8 \mathrm{a}$ & $0,48 \mathrm{a}$ & $3,9 \mathrm{a}$ & $3,9 a$ & $4,6 \mathrm{a}$ & $4,3 \mathrm{a}$ & $3,6 \mathrm{~b}$ & $4,1 \mathrm{~b}$ \\
\hline $\mathrm{NaCl}$ & $14,1 \mathrm{~b}$ & $36,2 \mathrm{~b}$ & $48,7 \mathrm{~b}$ & $21,9 a b$ & $0,37 \mathrm{~b}$ & $3,9 \mathrm{a}$ & $3,8 \mathrm{a}$ & $4,0 \mathrm{a}$ & $3,9 \mathrm{a}$ & $4,0 \mathrm{~b}$ & $4,4 a b$ \\
\hline $\mathrm{KCl}$ & $15,9 \mathrm{a}$ & $39,8 \mathrm{ab}$ & 56,9 a & $21,1 \mathrm{~b}$ & $0,38 \mathrm{ab}$ & $3,9 \mathrm{a}$ & $4,5 \mathrm{a}$ & $3,9 \mathrm{a}$ & $4,6 \mathrm{a}$ & $5,0 \mathrm{a}$ & $5,2 \mathrm{a}$ \\
\hline CV (\%) & 13,7 & 15,3 & 19,5 & 10,3 & 35,7 & & & & 2,8 & & \\
\hline
\end{tabular}

Médias seguidas de mesma letra na coluna não diferem entre si pelo teste de Tukey a $5 \%$ de probabilidade 
O DC apresentou diferença entre os sais somente nos potenciais $-1,2$ e $-1,6 \mathrm{MPa}$, reduzindo de forma semelhante com a solução de $\mathrm{CaCl}_{2} \mathrm{e} \mathrm{NaCl}$, sendo que no menor potencial o $\mathrm{KCl}$ foi similar ao $\mathrm{NaCl}$ (Tabela 2).

Verificou-se que a utilização do $\mathrm{KCl}$ proporcionou maior $\mathrm{DC}$ e $\mathrm{AF}$, o que poderia estar relacionado a maior necessidade de $\mathrm{K}^{+}$na fase inicial de desenvolvimento da planta, onde ocorre a máxima absorção desse nutriente, funcionando como um elemento de "arranque". De acordo com Franco et al. (1999), o maior índice de área foliar representa uma maior interceptação solar pelas plantas, resultando em elevada capacidade de produção de biomassa. Nesta biomassa pode-se incluir também o aumento do DC, que se relacionaria segundo Fancelli e Dourado Neto
(2000), com a maior capacidade das plantas de milho em armazenar fotoassimilados que contribuiriam para o melhor desenvolvimento da cultura, mesmo em condições adversas.

Semelhante ao que ocorreu no experimento em laboratório, $\mathrm{o} \mathrm{CaCl}_{2}$ comportou-se de forma inesperada, não sendo possível o ajuste de modelos matemáticos que expliquem o efeito dos potenciais osmóticos obtidos com esse sal no DC de plântulas de milho (Figura 3). Essas respostas diferenciadas ao $\mathrm{CaCl}_{2}$ podem ter ocorrido devido ao seu menor índice salino quando comparado aos demais sais, demonstrando menores efeitos à cultura para as concentrações estabelecidas, podendo as respostas estarem correlacionadas somente com os aspectos nutricionais do cálcio na planta.

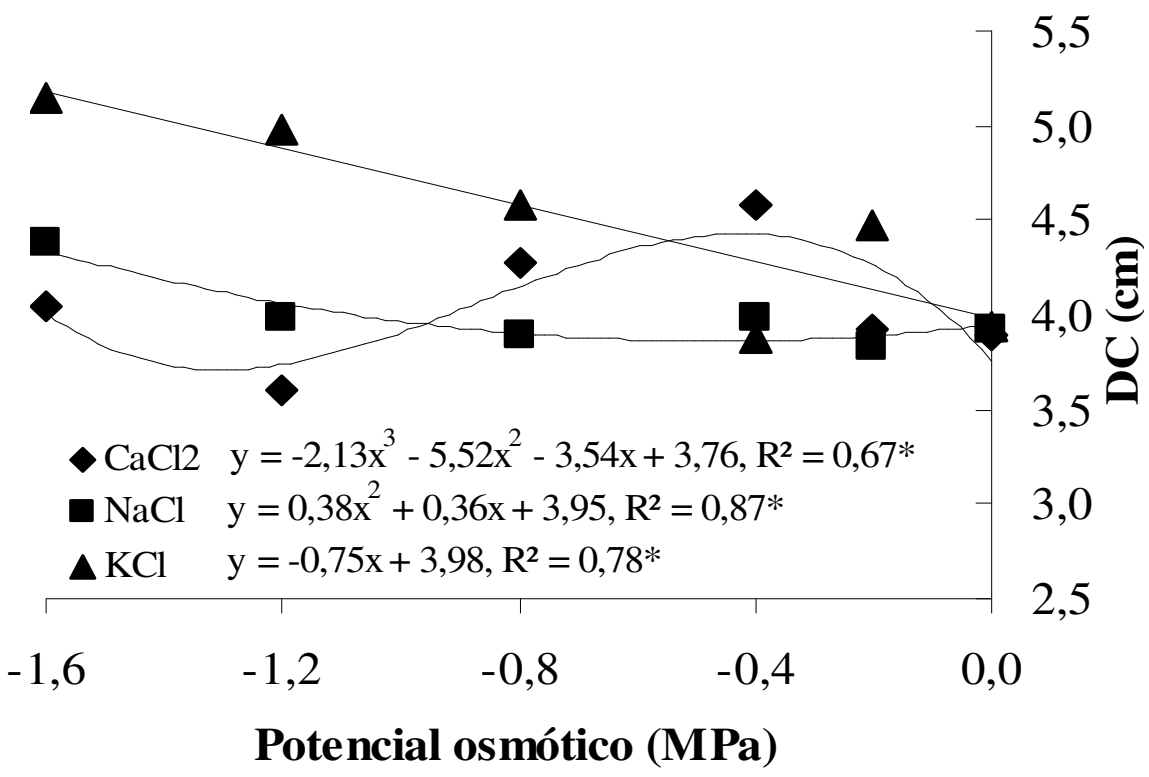

FIGURA 3. Diâmetro de colmo (DC) de milho sob estresse salino induzido por três sais em diferentes potenciais osmóticos, em casa de vegetação.

$\mathrm{O} \mathrm{KCl}$ proporcionou aumento do $\mathrm{DC}$ com a redução dos potenciais osmóticos, da ordem de $30 \%$ no menor potencial quando comparado a ausência do sal (Figura 3). Ocorreu pequena variação nos valores de DC com o $\mathrm{NaCl}$ até o potencial de $-0,47 \mathrm{MPa}$, a partir do qual foi observado maior incremento até $-1,6 \mathrm{MPa}$.

$\mathrm{O}$ melhor modelo que se ajustou ao $\mathrm{CR}$ nos potenciais osmóticos induzidos pelos sais foi o exponencial, sendo observado inicialmente um declínio mais expressivo com tendência posterior a estabilizar a redução no crescimento, mesmo com a utilização dos menores potenciais osmóticos (Figura 4). Esse comportamento em casa de vegetação foi diferente do observado em laboratório, onde de forma geral ocorreram acréscimos no crescimento radicular. Isso demonstra maior suscetibilidade das raízes ao estresse salino em condições de campo, possivelmente devido ao acúmulo dos sais próximo a região das raízes, ocasionando maiores efeitos sobre as plantas. Segundo Tôrres et al. (2004), os efeitos imediatos da salinidade, relacionam-se como a seca fisiológica, proveniente da diminuição osmótica, desbalanço nutricional, ocasionado pela inibição da absorção e transporte de nutrientes, bem como, os efeitos tóxicos de íons, particularmente cloro e sódio. 


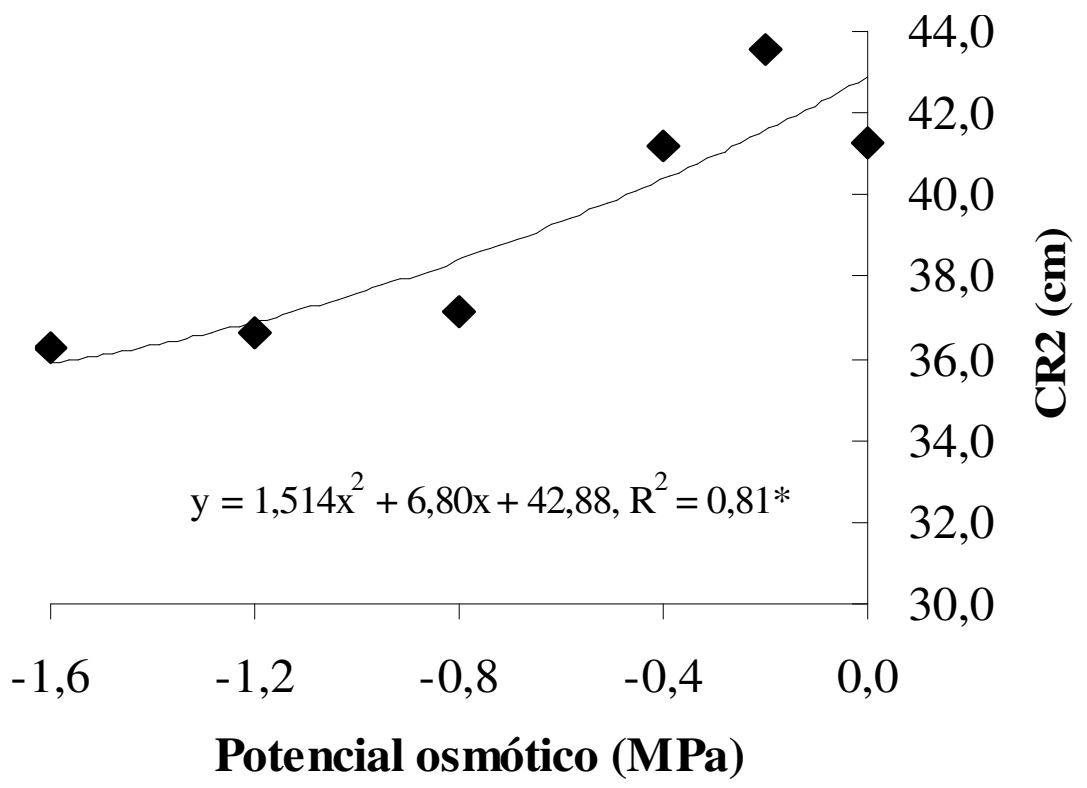

FIGURA 4. Valores médios do comprimento radicular (CR) de milho sob estresse salino induzido por $\mathrm{CaCl}_{2}, \mathrm{NaCl}^{\mathrm{e}}$ $\mathrm{KCl}$ em diferentes potenciais osmóticos, em casa de vegetação.

\section{CONCLUSÕES}

A germinação das sementes não é afetada pelo estresse salino. A diminuição do potencial osmótico nas soluções de $\mathrm{KCl}$ e $\mathrm{NaCl}$ causa decréscimos no comprimento de parte aérea e acréscimos no comprimento da raiz primária.

A condição de estresse provocada pelos sais proporciona comportamento diferenciado no vigor de plântulas de milho. $\mathrm{O}$ efeito salino do $\mathrm{NaCl}$ é maior nas características altura de planta, comprimento radicular, área foliar e massa seca de raiz.

\section{REFERÊNCIAS}

AMORIM, J.R.A.; FERNANDES, P.D.; GHEYI, H.R.; AZEVEDO, N.C. Efeito da salinidade e modo de aplicação da água de irrigação no crescimento e produção de alho. Pesquisa Agropecuária Brasileira, v.37, n.2, p.167-176, 2002.

ANDRADE, F.H. Analysis of growth and yield of maize, sunflower and soybean grown at Balcarce, Argentina. Field Crops Research, v.41, n.1, p.1-12, 1995.

AZEVEDO NETO, A.D.; BEZERRA NETO E.; BARRETO, L.P.; TABOSA, J.N., ANSELMO, O.C.; CAVALCANTI,
P.A. Efeito do estresse salino sobre cultivares de milho: I. Produção e alocação de fitomassa. In: CONGRESSO LATINOAMERICANO DA CIÊNCIA DO SOLO, 21, 1996, Águas de Lindóia. Resumos... Águas de Lindóia: SBCS, 1996.

AZEVEDO NETO, A.D.; TABOSA, J.N. Estresse salino em plântulas de milho: parte I análise do crescimento. Revista Brasileira de Engenharia Agrícola e Ambiental, v.4, n.2, p.159-164, 2000.

BRASIL. Ministério da Agricultura e Reforma Agrária. Secretaria Nacional de Defesa Agropecuária. Departamento Nacional de Produção Vegetal. Coordenação de Laboratório Vegetal. Regras para Análise de Sementes. Brasília, DF, 1992. 365p.

DICKMANN, L.; CARVALHO, M.A.C.; BRAGA, L.F.; SOUSA, M.P. Comportamento de sementes de girassol (Helianthus annuus L.) submetidas a estresse salino. Revista Ciências Agro-Ambientais, v.3, p.64-75, 2005.

FANCELli, A.L.; DOURADO-NETO, D. Produção de milho. Guaíba: Agropecuária, 2000. 360p.

FANCELLI, A.L.; DOURADO-NETO, D. Tecnologia da produção de milho. Piracicaba: ESALQ/USP, 1997. 174p.

FANTI, S.C.; PEREZ, S.C.J.G.A. Processo germinativo de 
sementes de paineira sob estresses hídrico e salino. Pesquisa Agropecuária Brasileira, v.39, n.9, p.903-909, 2004.

FERREIRA， L.G.R.; REBOUÇAS， M.A.A. Influência da hidratação/desidratação de sementes de algodão na superação de efeitos da salinidade na germinação. Pesquisa Agropecuária Brasileira, v.27, n.4, p.609-615, 1992.

FRANCIS, C.A.; RUTGER, J.N.; PALMER, A.F.E.A. Rapid method for plant leaf area estimation in maize (Zea mays). Crop Science, v.9, n.5, p.537-539, 1969.

FRANCO, O.L.; ENÉAS-FILHO, J.; PRISCO, J.T.; GOMES FILHO, E. Effects of $\mathrm{CaCl}_{2}$ on the growth and osmoregulator accumulation in $\mathrm{NaCl}$ stressed cowpea seedlings. Revista Brasileira de Fisiologia Vegetal, v.11, n.3, p.145-151, 1999.

LARCHER, W. Ecofisiologia vegetal. São Carlos: Rima, 2000. 529p.

MACHADO NETO, N.B.; CUSTÓDIO, C.C.; COSTA, P.R.; DONÁ, F.L. Deficiência hídrica induzida por diferentes agentes osmóticos na germinação e vigor de sementes de feijão. Revista Brasileira de Sementes, v.28, n.1, p.142148, 2006.
MOTERLE, L.M.; LOPES, F.C.; BRACCINI, A.L.; SCAPIM, C.A. Germinação de sementes e crescimento de plântulas de cultivares de milho-pipoca submetidas ao estresse hídrico e salino. Revista Brasileira de Sementes, v.28, n.3, p.169-176, 2006.

SALISBURY, F.B.; ROSS, C.W. Plant physiology. 4. ed. Belmont: Wadsworth, 1992. 682p.

SANTOS, V.L.M.; CALIL, A.C.; RUIZ, H.A.; ALVARENGA, E.M.; SANTOS, C.M. Efeito do estresse salino e hídrico na germinação e vigor de sementes de soja. Revista Brasileira de Sementes, v.14, n.2, p.189-194, 1992.

SHALHEVET, J.; HUCK, M.G.; SCHROEDER, B.P. Root and shoot growth responses to salinity in maize and soybean. Agronomy Journal, v.87, n.3, p.512-516, 1995.

TÔRRES，A.N.L.; PEREIRA， P.R.G.; TÔRRES， J.T.; GALLOTTI, G.J.M.; PILATI, J.A.; REBELO, J.A.; HENKELS, H. A salinidade e suas implicações no cultivo de plantas. Florianópolis: Epagri, 2004. 54p. (Epagri. Documentos, 215). 